\title{
Optimizing the Amino Acid Sequences of Peptides and Improving Their Specificity of Binding to SH3 Domains of Target Proteins
}

\author{
Yanrong Ren', Qiang Wang ${ }^{1}$, Xiaobo $\mathrm{Li}^{2}$ \\ ${ }^{1}$ School of Biological and Chemical Engineering, Chongqing University of Education, Chongqing 400067, P. R. China \\ ${ }^{2}$ Human Resources Office, Chongqing University of Education, Chongqing 400067, P. R. China
}

\begin{abstract}
Introduction: It is always a crucial challenge in biotechnology to avoid promiscuous binding between an anticancer peptide and multiple $\mathrm{SH} 3$ domains, thus reducing potential toxic effects. In spite of a great deal of experimental efforts, the association between amino acid sequence and binding specificity of peptide remained largely unknown. Aim: The purpose of this study was to optimize the amino acid sequence of peptide ligands and render high specificity towards designated therapeutic targets. Results: By exploring peptide ligands in MINT database and utilizing SH3Peplnt tool for in silico peptide-target binding, here we investigated how the amino acid sequence of a peptide determined its specificity of binding to the $\mathrm{SH} 3$ domain of $\mathrm{c}$-Src protein. We found that the $5^{\text {th }}$ and the $6^{\text {th }}$ residues of proline-rich motif had large influence on peptide-target binding. By purposely modifying the amino acid at these two key positons, the overall level of binding promiscuity was significantly reduced. Conclusion: Taken together, these findings corroborated that the $\mathrm{SH} 3$ domain of c-Src protein can discern subtle differences in the amino acid sequence of ligands, which provided a unique opportunity for rational design of therapeutic peptides.
\end{abstract}

Key words: SH3 domain; c-Src; promiscuity; specificity; peptide rational design

\section{INTRODUCTION}

As one of the major causes of death worldwide ${ }^{1}$, cancer is characterized by uncontrolled division of tumor cells and invasion into other tissues. ${ }^{2}$ Chemotherapy is adopted as one of the major approaches to treat cancer, by which a cytotoxic agent is delivered to the cancer cells. However, traditional chemotherapeutical drugs target tumor cells by disrupting necessary cellular functions of normal cells, thus leading to a variety of adverse effects. ${ }^{3}$ In addition, multidrug resistance in patients can also cause failure of chemotherapy. ${ }^{4}$ Because of that, cancer treatment using peptides is emerging as a more targeted to circumvent the problems of conventional chemotherapy. ${ }^{5}$ As molecules formed by combinations of amino acids linked by peptide bonds through the dehydration-condensation reaction, peptides are characterized by many pharmacological advantages, such as smaller size, ease of synthesis and modification, high tumorpenetrating ability, and favorable biocompatibility. ${ }^{6}$ In recent years, a number of peptide-based therapies have been tested in both in vitro and in vivo experimental models and applied to treat various types of cancer. ${ }^{7}$ During the process of developing peptidebased drugs, many proteins have been selected as potential drug targets due to their critical roles in the pathogenesis of cancers. Of the various protein targets chosen, c-Src is an extensively studied kinase oncogene in academia and industry. ${ }^{8}$ c - Src is a non-receptor tyrosine kinase that involved in intracellular signaling and
Submission Date: 30-09-2016; Revision Date: 03-11-2016; Accepted Date: 28-11-2016

DOI: 10.5530/ijper.50.1.7 Correspondence: Yanrong Ren,

Address: 9 Xuefu Avenue, Nan'an District, Chongqing University of Education, Chongqing 400067,

P. R. China

Ph.no: $+86(023) 86380026$ Fax: +86(023) 62658983

E-mail: ren_sci@sina.com

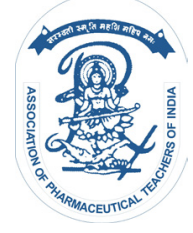

www.ijper.org 
regulates the phosphorylation of multiple proteins. ${ }^{9}$ Aberrant activation of c-Src is found to be correlated with transformation, proliferation, tumor angiogenesis, and malignant progression of a wide variety of human cancers. ${ }^{10,11}$ These properties render c-Src a target for a series of chemical anticancer drugs. While c-Src inhibitors effectively arrest the cycle progression of tumor cells ${ }^{12,13}$, they also induce serious adverse reactions as most conventional chemotherapy agents. ${ }^{14,15}$

The c-Src protein is composed of an N-terminal myristoylation sequence attached to the SH4 domain, a unique region followed by $\mathrm{SH} 3$ and $\mathrm{SH} 2$ domains, a linker region, a kinase domain $\mathrm{SH} 1$ domain, and a C-terminal regulatory domain. ${ }^{16,17}$ While the kinase domain serves as the target for many chemical anticancer drugs, the SH3 domain is receiving increasing attention in recent years for its involvement in multiple important cellular processes, including signal transduction, cytoskeleton regulation, and membrane trafficking. ${ }^{18}$ In the meantime, SH3 domains generally mediate peptide-protein interactions through the recognition of proline-rich motifs in the amino acid sequence of peptide. ${ }^{19,20}$ Therefore, the SH3 domain of c-Src protein is considered as a potential target of therapeutic peptides with antitumor activity. ${ }^{21}$

However, it must be noticed that the $\mathrm{SH} 3$ domains may, in a sense, be highly versatile in interacting with peptide ligands. For example, SH3 domains of different proteins may commonly favor a given consensus motif. As a result, one peptide ligand may accidentally bind to multiple protein targets via $\mathrm{SH} 3$ domains, thus playing diverse and unpredictable roles in the cell. ${ }^{22}$ Therefore, it is always crucial to avoid promiscuous binding between a candidate peptide and multiple $\mathrm{SH} 3$ domains, in order to reduce potential toxic effects. Although the consensus amino acid sequence of proline-rich motif serves as an anchor for interacting with most $\mathrm{SH} 3$ domains, the specificity may vary between individual peptides, which is profoundly influenced by residues in the core motif. ${ }^{20}$ Because of that, the amino acid sequence of a candidate peptide can be elaborately designed, so as to render high affinity and specificity against designated therapeutic targets. $^{23}$

In spite of a great deal of experimental efforts, ${ }^{20}$ the association between amino acid sequence and binding specificity of peptide remained largely unknown. This situation motivated us to make efforts on this issue from a computational perspective. By exploring online peptide database and utilizing bioinformatics tool, we investigated how the amino acid sequence of a peptide may influence its binding specificity towards the SH3 domain of c-Src protein. We primarily retrieved a set of prototype peptides that have already been experimentally validated for binding to the $\mathrm{SH} 3$ domain of c-Src protein, among which we identified several peptides binding to fewer targets. These peptides with better binding specificity exhibited some common features in amino acid sequence. Based on that, we purposely optimized the amino acid sequence of all prototype peptides. The results showed that such optimization effectively hindered promiscuous peptide-target binding, which provided a practical way of reducing the safety risks of therapeutic peptides.

\section{MATERIALS AND METHODS \\ Preparation of prototype peptides}

We primarily searched the Molecular INTeraction (MINT) database (http://mint.bio.uniroma2.it/mint/ Welcome.do) for experimentally validated molecules interacting with the SH3 domain of human c-Src protein, including proteins, drugs and peptides. Among these molecules, only peptides were retained for further analysis. The peptides with class I canonical prolinerich motifs were recognized with 'stringr' package (https://cran.r-project.org/web/packages/stringr/) in the statistical environment $\mathrm{R}$. The consensus sequence for class I proline-rich motifs was denoted as $+\mathrm{x} Ф$ Р where $\mathrm{x}$ represented any naturally occurring amino acid, $\Phi$ represented a hydrophobic amino acid (i.e., alanine, isoleucine, leucine, methionine, phenylalanine, proline, tryptophan, valine or glycine) and + represented a positively charged amino acid (normally arginine or lysine). The information of amino acid properties (i.e., hydrophobic and positively charged) was queried in TP53 Database of International Agency for Research on Cancer (http://p53.iarc.fr/AAProperties.aspx).

\section{Prediction of peptide-target interactions}

The prototype peptides were submitted to MoDPepInt (Modular Domain Peptide Interaction, http://modpepint.informatik.uni-freiburg.de/), an interactive web server with multiple bioinformatics tools for the prediction of domain-peptide binding. In this study, we utilized the SH3PepInt tool of MoDPepInt server, which was based on efficient and sophisticated graph kernel technique and did not require pre-alignment of the peptides. Trained on published peptide-protein interaction data with support vector machines, SH3PepInt can predict the $\mathrm{SH} 3$ domains potentially interacting with the peptide of interest. The query sequences of all prototype peptides were supplied in a FASTA format. Then, the output results, as a downloadable table, presented the potential interactions between prototype peptide and 69 human 
SH3 domains (including c-Src protein). The specificity/ promiscuity of domain-peptide binding was measured by the number of $\mathrm{SH} 3$ domains predicted to interact with a certain prototype peptide. The more domains except for c-Src a prototype peptide was predicted to bind to, the lower binding specificity (i.e., the higher binding promiscuity) it indicated.

\section{Domain-peptide docking}

The interaction between prototype peptide and target SH3 domain was modeled using the CABS-dock web server (http://biocomp.chem.uw.edu.pl/CABSdock), a highly efficient tool for the flexible docking of peptides to proteins. Peptide sequence was entered in singleletter amino acid code. Protein domain structure was provided as Protein Data Bank (PDB) code along with the chain identifier. Then, possible structures of the peptide were generated and randomly placed on the surface of the target domain. Within the set of resulting docking models, the top 10 selected models with the highest accuracy were presented by CABS-dock in detail. The accuracy of docking models was assessed with the rootmean-square deviation (RMSD) between predicted and experimental peptide structures, i.e., lower RMSD value indicated higher quality of prediction.

\section{RESULT AND DISCUSSION}

\section{The association between amino acid sequences and domain-peptide binding}

To investigate the correlation between amino acid sequence and promiscuous peptide-target binding, we collected a set of prototype peptides for analysis (see Materials and Methods). First of all, we searched the Molecular INTeraction (MINT) database, ${ }^{24}$ so as to obtain a list of molecules that have been experimentally validated to interact with the $\mathrm{SH} 3$ domain of human c-Src protein. These molecules included proteins, drugs and peptides, among which only 10 peptides with class I canonical proline-rich motifs were retained for analysis. Then, the 10 prototype peptides were uploaded to the MoDPepInt (Modular Domain Peptide Interaction $)^{25}$ web server. SH3PepInt was a tool provided by MoDPepInt, ${ }^{26}$ which used graph kernel approach to perform alignment-free prediction of domain-peptide interaction. Therefore, by querying the amino acid sequence, we were enabled to identify $\mathrm{SH} 3$ domains potentially interacting with the prototype peptides (see Materials and Methods).

The output results showed that all prototype peptides were predicted to bind to the $\mathrm{SH} 3$ domain of c-Src protein, suggesting the consistency between SH3PepInt models and experiments. Besides c-Src, other proteins with $\mathrm{SH} 3$ domain were also predicted to interact with some of the prototype peptides. And the number of such promiscuous interactions varied greatly between peptides (Table 1). While some peptides only interacted with a few proteins (e.g., peptide 8 and peptide 5), some other peptides could bind to up to 25 proteins (e.g., peptide 6 and peptide 2). Interestingly, we noticed that those peptides showing relatively higher binding specificity tended to (1) have leucine (with symbol L) as the $5^{\text {th }}$ residue of proline-rich motif (e.g., peptides No. 8, No. 5 and No. 4), and (2) have proline (with symbol $\mathrm{P}$ ) as the $6^{\text {th }}$ residue of proline-rich motif (e.g., peptides No. 8 and No. 4). The above patterns (Figure 1) indicated that amino acid sequence of proline-rich motif may be correlated to the degree of promiscuity.

\section{Optimization of amino acid sequences and improvement of binding specificity}

In view of the correlation between the amino acid sequence in proline-rich motif and the promiscuity of domain-peptide binding, we hypothesized that certain amino acid residues of the prototype peptides could be purposely modified to improve binding specificity towards c-Src protein. We tested two parallel schemes of optimization. First, we substituted leucine for the $5^{\text {th }}$ residue of proline-rich motif. Second, we replaced the $6^{\text {th }}$ residue of proline-rich motif with proline. Except for prototype peptides No. 8, No. 5 and No. 4 that originally had leucine as the $5^{\text {th }}$ residue of proline-rich motif, the first scheme applied to the other 7 prototype peptides. For 6 out of these 7 peptides, the number of promiscuous interactions declined after optimization (Figure 2, Table S1). The second scheme applied to 8 prototype peptides, except for peptides No. 8 and No. 4. A decline in the number of promiscuous interactions was observed in 7 out of these 8 peptides (Figure 3, Table S2).

Such observations demonstrated that the $5^{\text {th }}$ and the $6^{\text {th }}$ residues of proline-rich motif can largely influence on peptide-target binding. Therefore, we combined the above two schemes and modified both the $5^{\text {th }}$ and the $6^{\text {th }}$ residues. A side-by-side comparison was made between the original and the modified peptides (Figure 4, Table S3). One-tailed paired t-test indicated that the overall level of promiscuity of prototype peptides was significantly reduced after modification ( $\mathrm{P}$-value $=$ 0.0075). These findings came together to suggest that c-Src binding specificity of peptide ligands can be greatly determined by the amino acid types at key positions in the proline-rich motif, which provided a unique oppor- 
tunity for sequence modification and rational design of therapeutic peptides.

\section{Validating modified peptides with domain-peptide docking}

Molecular docking approach has been widely adopted to understand ligand-protein interaction. ${ }^{27}$ So the above results were validated by reproducing conformation of docked peptide in crystal structure of target SH3 domain. As a typical example, peptide No. 5 was originally predicted to bind to the $\mathrm{SH} 3$ domain of hematopoietic cell kinase (HCK). According to the calculation of MoDPepInt, the probability of such binding significantly decreased after modifying the $5^{\text {th }}$ and the $6^{\text {th }}$ residues of proline-rich motif. Therefore, the original and modified sequences of peptide No. 5, along with the 3D structure of HCK SH3 domain (PDB ID: 4HCK), were entered into the CABS-dock web server. ${ }^{28} \mathrm{CABS}$-dock performed highly efficient and flexible docking simulation to search for possible binding conformations. The accuracy of docking models was measured by the root-mean-square deviation (RMSD). The top 10 models with the highest accuracy (i.e., the lowest RMSD value) were selected as final results (see Materials and Methods). It was shown that the original and modified peptides had different binding positions and orientations on the surface of HCKSH3 domain (Figure 5A and 5B). Regarding the top 10 best models (Figure 5C), the modified peptide exhibited significantly higher RMSD, namely lower quality of binding, than the original peptide $(\mathrm{P}$-value $=$ $\left.5.99 \times 10^{-5}\right)$. These results supported the prediction that modifying both the $5^{\text {th }}$ and the $6^{\text {th }}$ residues of prolinerich motif may prevent peptide No. 5 from binding to HCK SH3 domain, thus lowering the promiscuity of peptide No. 5 .

\section{Implication of the current results}

Peptides are ideal molecules for drug development because of low molecular weight and good cellular uptake. Over these years, the application of peptides is rapidly growing in a variety of therapeutic areas, with the number of peptide drugs under clinical trials increasing steadily. The number has climbed from 1.2 per year in the 1970 s to 16.8 per year in the 2000 s. ${ }^{6}$ Currently, more than 60 peptide drugs have been approved for marketing and several hundreds of novel therapeutic peptides are under preclinical or clinical development. ${ }^{5}$ The key contributor to the success of these peptides is their potent and specific, yet safe, modes of action.

As a class of promising anticancer agents, peptides bind to key proteins in tumor cells with low toxicity to normal tissues. ${ }^{29}$ This tumor-targeting ability of peptides is

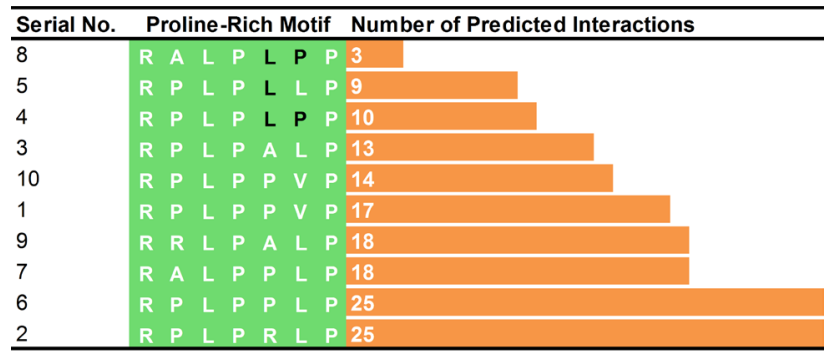

Figure 1: The association between the 5th and the 6th residues of proline-rich motif and binding specificity of prototype peptides.

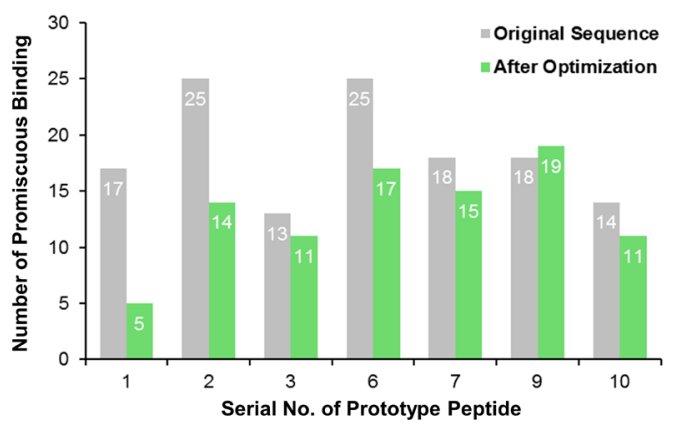

Figure 2: Most peptides, except for peptide No. 9, exhibited better binding specificity after optimizing the 5 th residue of proline-rich motif.

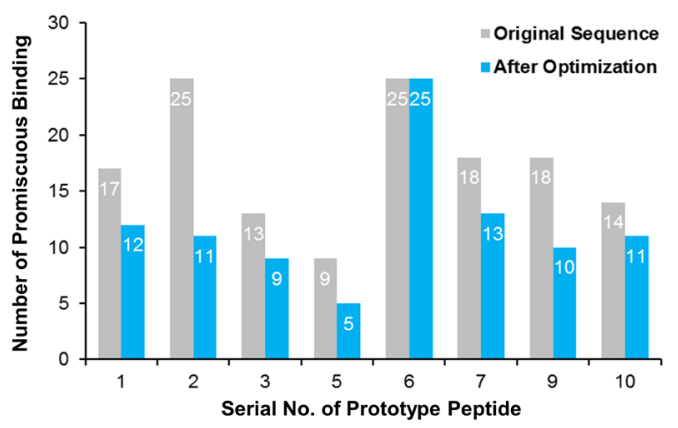

Figure 3: Most peptides, except for peptide No. 6, exhibited better binding specificity after optimizing the 6 th residue of proline-rich motif.

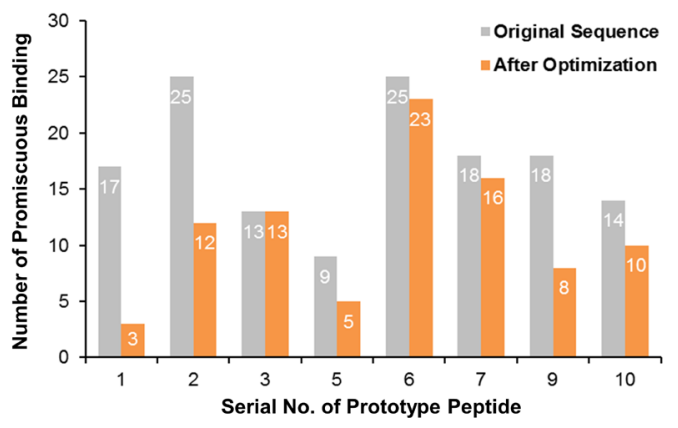

Figure 4: Most peptides, except for peptide No. 3, exhibited better binding specificity after optimizing the 5 th and the 6 th residues of proline-rich motif. 
A

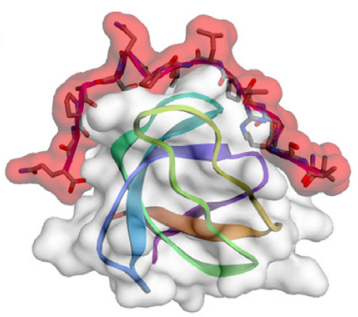

B

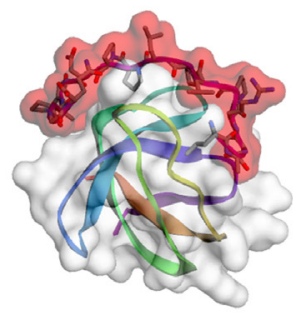

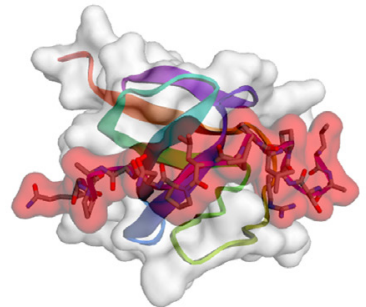
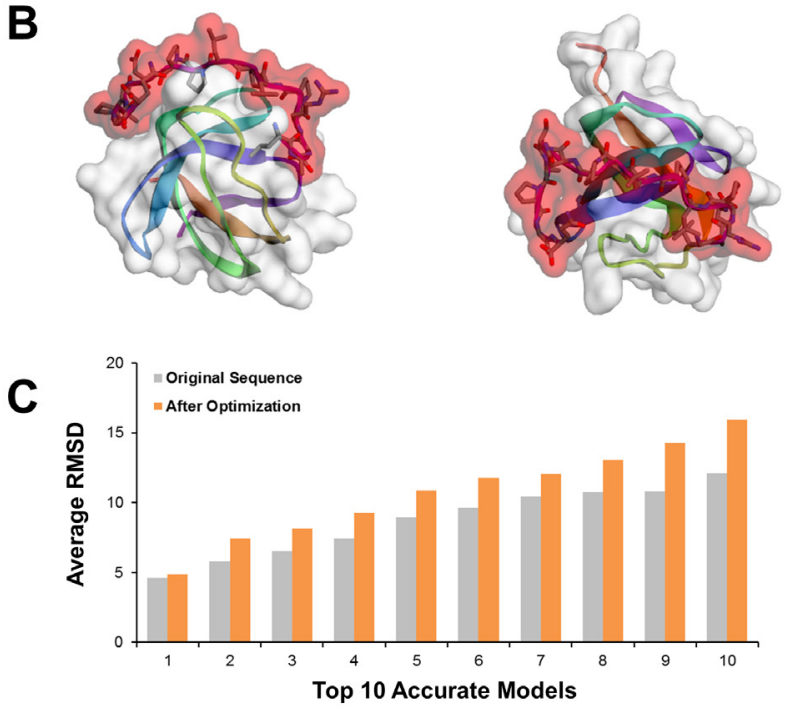

Figure 5: Domain-peptide binding validated by molecular docking. (A) The best fitted binding model of original peptide No. 5 and HCK SH3 domain. (B) The best fitted binding model of modified peptide No. 5 and HCK SH3 domain. (C) The docking RMSD values of original and modified sequences of peptide No. 5.

determined by their complementary binding to a variety of key proteins in tumor cells. For instance, the positively charged arginine and lysine in peptide can selectively form hydrogen bonds with the negatively charged components of target protein domains. ${ }^{30}$ Nonetheless, these complementary properties may not always guarantee perfect specificity of peptide-target binding. For example, SH3 domains have become a well-known and promising anti-cancer target of peptide ligands with proline-rich motifs. But SH3 domains are one of the most abundant domain families encoded in eukaryotic genomes. So far, at least $300 \mathrm{SH} 3$ domains have been identified in the human proteome. ${ }^{31}$ As a result of highly conserved amino acid sequence and structure of different $\mathrm{SH} 3$ domains, one proline-rich peptide can be recognized by multiple proteins with $\mathrm{SH} 3$ domain. The promiscuous nature of $\mathrm{SH} 3$ domains in binding to proline-rich peptides may lead to unexpected adverse reactions due to impact on various cell-signaling pathways and biological functions. ${ }^{32}$ So it is an open challenge in biotechnology to design peptide ligands with a high specificity of binding to the $\mathrm{SH} 3$ domain of designated target (e.g., c-Src) and without interacting with other proteins.

In the present study on c-Src protein, we demonstrated that subtle alterations in the amino acid sequence could significantly change the specificity of binding to the target $\mathrm{SH} 3$ domain. We primarily searched MINT database for a set of prototype peptides, which have been experimentally validated for binding to the $\mathrm{SH} 3$ domain of c-Src protein. Relying on the SH3PepInt tool, we predicted the interaction between the peptides and various SH3 domains. Then, by comparing the amino acid sequence of prototype peptides with relatively high and low specificity of binding to c-Src protein, we found that leucine as the $5^{\text {th }}$ residue and proline as the $6^{\text {th }}$ residue of proline-rich motif could render prototype peptide a reduced promiscuity. In the last step, we purposely modified the $5^{\text {th }}$ and the $6^{\text {th }}$ residues of relevant peptides, which led to significantly better specificity of peptide-target binding. The above results showed that promiscuous binding of peptide molecule can be effectively ameliorated by rational design.

Based on various public crystallographic data, ${ }^{33-38}$ the SH3 domain has been thoroughly researched and broadly recognized as one of the best available systems for the examination of ligand-protein interactions. For example, Larson et al. constructed a diverse alignment of $\mathrm{SH} 3$ domain sequences. ${ }^{39}$ By analyzing conservative structural features within this alignment, several positions in the domain were identified for mediating the peptide-binding function. The existence of such key positions implied that the recognition of peptide ligands might be systematically explained, ${ }^{40,41}$ which effectively facilitated experiments of rational ligand designing. Alexandropoulos et al. found specific proline-rich sequences prone to bind to Fyn, Lyn, and Hck SH3 domains, respectively. ${ }^{20}$ Pisabarro et al. designed mutations in peptide, so that the affinity for Abl SH3 domain was selectively increased by 20 -fold. ${ }^{42}$ And Ferguson et al. used phage display for ligand optimization and obtained a peptide 1000 -fold increased affinity for the SEM-5 SH3 domain. ${ }^{43}$ Here we provided a novel clue as to increasing the specificity of binding to $\mathrm{SH} 3$ domain. The current results will inspire more subsequent work on optimization of amino acid sequence, so as to improve the safety of therapeutic peptides.

Despite of useful information provided by the present study, more efforts are required to address some limitations of the current results. First, the basis of this study was the prototype peptides retrieved from MINT database, with which we found the important role played by the $5^{\text {th }}$ and the $6^{\text {th }}$ residues of proline-rich motif. However, the number of available prototype remained 
relatively low for higher power of statistical tests. More work, such as literature searching and text mining, will be required to collect more information about prototype peptides proved to bind to the $\mathrm{SH} 3$ domain of human c-Src protein. Second, with a larger set of prototype peptides, more patterns of amino acid sequences related to peptide-target binding specificity can be explored. Apart from the $5^{\text {th }}$ and the $6^{\text {th }}$ residue, other residues in or flanking the proline-rich motif should also be investigated using our method. Third, the current results of peptide-target binding were mainly based on in silico prediction, which often led to alternate results in reality. An inconsistent track record of docking-based ligand discovery raised the concern about the reliability. For instance, it was reported that fewer than $20 \%$ of docking screens were eventually supported by crystal structure identified with experiments. ${ }^{44}$ In particular, those small molecules, such as peptides composed of a few amino acids, are found to be docked less reliably. ${ }^{45}$ Therefore, besides calculating the binding orientations and free energies. the optimized peptides need to be artificially synthesized and experimentally assayed for binding affinity against targets of interest. ${ }^{46}$

\section{CONCLUSION}

Taken together, by analyzing the promiscuity of peptidetarget binding, we corroborated the ability of the SH3 domain of c-Src protein to discern subtle differences in the amino acid sequence of peptide ligands. Based on that, we virtually optimized the proline-rich motifs of relevant peptides and improved the binding specificity. Further computational and experimental efforts will be required to validate and expand current results, which can be applied to the rational design of peptide-based anticancer drugs.

\section{ACKNOWLEDGEMENT}

Front and Applied Fundamental Research Plan of Chongqing Science \& Technology Commission (No. cstc2014jcyjA10104); the Program for Innovative Research Team in Chongqing University of Education (No. KYC-cxtd03-20141002) and the Project Foundation of Chongqing University of Education (No 16kjpt08) supported this work.

\section{REFERENCES}

1. Jemal A, Bray F, Center MM, Ferlay J, Ward E, Forman D. Global cancer statistics. CA: a cancer journal for clinicians. 2011;61:69-90. https://doi. org/10.3322/caac.20107.

2. Vogelstein B, Kinzler KW. Cancer genes and the pathways they control. Nature medicine. 2004;10:789-99.https://doi.org/10.1038/nm1087 PMid:15286780.
3. Narayan V, Vaughn D. Pharmacokinetic and toxicity considerations in the use of neoadjuvant chemotherapy for bladder cancer. Expert opinion on drug metabolism \& toxicology. 2015;11:731-42.https://doi.org/10.1517/17425255. 2015.1005600 PMid:25604887.

4. Huang W, Seo J, Willingham SB, Czyzewski AM, Gonzalgo ML, Weissman IL, et al. Learning from host-defense peptides: cationic, amphipathic peptoids with potent anticancer activity. PloS one. 2014;9:e90397. https://doi. org/10.1371/journal.pone.0090397 PMid:24587350 PMCid:PMC3938723.

5. Fosgerau K, Hoffmann T. Peptide therapeutics: current status and future directions. Drug discovery today. 2015;20:122-8. https://doi.org/10.1016/j. drudis.2014.10.003 PMid:25450771.

6. Borghouts C, Kunz C, Groner B. Current strategies for the development of peptide-based anti-cancer therapeutics. Journal of peptide science : an official publication of the European Peptide Society. 2005;11:713-26. https:// doi.org/10.1002/psc.717 PMid:16138387.

7. Boohaker RJ, Lee MW, Vishnubhotla P, Perez JM, Khaled AR. The use of therapeutic peptides to target and to kill cancer cells. Current medicinal chemistry. 2012;19:3794-804.https://doi.org/10.2174/092986712801661004 PMid:22725698 PMCid:PMC4537071.

8. Okamoto W, Okamoto I, Yoshida T, Okamoto K, Takezawa K, Hatashita E, et al. Identification of c-Src as a potential therapeutic target for gastric cancer and of MET activation as a cause of resistance to c-Src inhibition. Molecular cancer therapeutics. 2010;9:1188-97. https://doi.org/10.1158/1535-7163. MCT-10-0002 PMid:20406949.

9. Kim LC, Song L, Haura EB. Src kinases as therapeutic targets for cancer. Nature reviews Clinical oncology. 2009;6:587-95. https://doi.org/10.1038/ nrclinonc.2009.129 PMid:19787002.

10. Yeatman TJ. A renaissance for SRC. Nature reviews Cancer. 2004;4:470-80. https://doi.org/10.1038/nrc1366 PMid:15170449.

11. Irby RB, Yeatman TJ. Role of Src expression and activation in human cancer. Oncogene. 2000;19:5636-42.https://doi.org/10.1038/sj.onc.1203912 PMid:11114744.

12. Johnson FM, Saigal B, Talpaz M, Donato NJ. Dasatinib (BMS-354825) tyrosine kinase inhibitor suppresses invasion and induces cell cycle arrest and apoptosis of head and neck squamous cell carcinoma and non-small cell lung cancer cells. Clinical cancer research : an official journal of the American Association for Cancer Research. 2005;11:6924-32. https://doi. org/10.1158/1078-0432.CCR-05-0757 PMid:16203784.

13. Nautiyal J, Majumder P, Patel BB, Lee FY, Majumdar AP. Src inhibitor dasatinib inhibits growth of breast cancer cells by modulating EGFR signaling. Cancer letters. 2009;283:143-51.https://doi.org/10.1016/j. canlet.2009.03.035 PMid:19398150.

14. Conchon M, Freitas CM, Rego MA, Braga Junior JW. Dasatinib - clinical trials and management of adverse events in imatinib resistant/intolerant chronic myeloid leukemia. Revista brasileira de hematologia e hemoterapia. 2011;33:131-9. https://doi.org/10.5581/1516-8484.20110034 PMid:23284261 PMCid:PMC3520638.

15. Brunner AM, Costa DB, Heist RS, Garcia E, Lindeman NI, Sholl LM, et al. Treatment-related toxicities in a phase II trial of dasatinib in patients with squamous cell carcinoma of the lung. Journal of thoracic oncology: official publication of the International Association for the Study of Lung Cancer. 2013;8:1434-7.https://doi.org/10.1097/JTO.0b013e3182a47162 PMid:24128713 PMCid:PMC3801424.

16. Sen B, Johnson FM. Regulation of SRC family kinases in human cancers. Journal of signal transduction. 2011;2011:865819. https://doi. org/10.1155/2011/865819PMid:21776389 PMCid:PMC3135246.

17. Kaneko T, Li L, Li SS. The SH3 domain--a family of versatile peptide- and protein-recognition module. Frontiers in bioscience : a journal and virtual library. 2008;13:4938-52. https://doi.org/10.2741/3053 PMid:18508559.

18. Cesareni G, Panni S, Nardelli G, Castagnoli L. Can we infer peptide recognition specificity mediated by SH3 domains? FEBS letters. 2002;513:38-44. https:// doi.org/10.1016/S0014-5793(01)03307-5.

19. Feng S, Chen JK, Yu H, Simon JA, Schreiber SL. Two binding orientations for peptides to the Src SH3 domain: development of a general model for SH3-ligand interactions. Science. 1994;266:1241-7.https://doi.org/10.1126/ science.7526465 PMid:7526465.

20. Alexandropoulos K, Cheng G, Baltimore D. Proline-rich sequences that bind to Src homology 3 domains with individual specificities. Proceedings of the 
NationalAcademy of Sciences of the United States ofAmerica. 1995;92:3110-4 https://doi.org/10.1073/pnas.92.8.3110 PMid:7536925 PMCid:PMC42114.

21. Vidal M, Gigoux V, Garbay C. SH2 and $\mathrm{SH} 3$ domains as targets for antiproliferative agents. Critical reviews in oncology/hematology. 2001;40:175-86. https://doi.org/10.1016/S1040-8428(01)00142-1.

22. Li SS. Specificity and versatility of $\mathrm{SH} 3$ and other proline-recognition domains: structural basis and implications for cellular signal transduction. The Biochemical journal. 2005;390:641-53.https://doi.org/10.1042/BJ20050411 PMid:16134966 PMCid:PMC1199657.

23. Geng L, Wang Z, Yang X, Li D, Lian W, Xiang Z, et al. Structure-based Design of Peptides with High Affinity and Specificity to HER2 Positive Tumors. Theranostics. 2015;5:1154-65.https://doi.org/10.7150/thno.12398 PMid:26284145 PMCid:PMC4533098.

24. Licata L, Briganti L, Peluso D, Perfetto L, lannuccelli M, Galeota E, et al. MINT, the molecular interaction database: 2012 update. Nucleic acids research. 2012;40:D857-61. https://doi.org/10.1093/nar/gkr930 PMid:22096227 PMCid:PMC3244991.

25. Kundu K, Mann M, Costa F, Backofen R. MoDPeplnt: an interactive web server for prediction of modular domain-peptide interactions. Bioinformatics. 2014;30:2668-9. https://doi.org/10.1093/bioinformatics/btu350 PMid:24872426 PMCid:PMC4155253.

26. Kundu K, Costa F, Backofen R. A graph kernel approach for alignmentfree domain-peptide interaction prediction with an application to human SH3 domains. Bioinformatics. 2013;29:i335-43.https://doi.org/10.1093/ bioinformatics/btt220 PMid:23813002 PMCid:PMC3694653.

27. Rohit H M, Ashok D T, Vijaykumar R, Kashniyal K. Molecular Docking Study of Cassia tora, Brassica campestris and Calotropis procera as Acetylcholinesterase Inhibitor. Indian Journal of Pharmaceutical Education and Research. 2016;50:116-22. https://doi.org/10.5530/ijper.50.1.15.

28. Kurcinski M, Jamroz M, Blaszczyk M, Kolinski A, Kmiecik S. CABS-dock web server for the flexible docking of peptides to proteins without prior knowledge of the binding site. Nucleic acids research. 2015;43:W419-24. https://doi. org/10.1093/nar/gkv456 PMid:25943545 PMCid:PMC4489223.

29. Wu D, Gao Y, Qi Y, Chen L, Ma Y, Li Y. Peptide-based cancer therapy: opportunity and challenge. Cancer letters. 2014;351:13-22. https://doi. org/10.1016/j.canlet.2014.05.002 PMid:24836189.

30. Farkhani SM, Valizadeh A, Karami H, Mohammadi S, Sohrabi N, Badrzadeh F. Cell penetrating peptides: efficient vectors for delivery of nanoparticles, nanocarriers, therapeutic and diagnostic molecules. Peptides. 2014;57:78-94. https://doi.org/10.1016/j.peptides.2014.04.015 PMid:24795041.

31. Karkkainen S, Hiipakka M, Wang JH, Kleino I, Vaha-Jaakkola M, Renkema $\mathrm{GH}$, et al. Identification of preferred protein interactions by phage-display of the human Src homology-3 proteome. EMBO reports. 2006;7:186-91. https:// doi.org/10.1038/sj.embor.7400596 PMid:16374509 PMCid:PMC1369250.

32. Agrawal V, Kishan KV. Promiscuous binding nature of $\mathrm{SH} 3$ domains to their target proteins. Protein and peptide letters. 2002;9:185-93. https://doi. org/10.2174/0929866023408760 PMid:12144515.

33. Camara-Artigas A, Ortiz-Salmeron E, Andujar-Sanchez M, Bacarizo J, Martin-Garcia JM. The role of water molecules in the binding of class I and II peptides to the $\mathrm{SH} 3$ domain of the Fyn tyrosine kinase. Acta crystallographica Section F, Structural biology communications. 2016;72:707-12.https://doi. org/10.1107/S2053230X16012310. PMid:27599862.
34. Bhatt VS, Zeng D, Krieger I, Sacchettini JC, Cho JH. Binding Mechanism of the N-Terminal SH3 Domain of Crkll and Proline-Rich Motifs in cAbl. Biophysical journal. 2016;110:2630-41.https://doi.org/10.1016/j. bpj.2016.05.008 PMid:27332121.

35. Bacarizo J, Martinez-Rodriguez S, Camara-Artigas A. Structure of the c-Src$\mathrm{SH} 3$ domain in complex with a proline-rich motif of NS5A protein from the hepatitis C virus. Journal of structural biology. 2015;189:67-72.https://doi. org/10.1016/j.jsb.2014.11.004 PMid:25447263.

36. Bacarizo J, Martinez-Rodriguez S, Martin-Garcia JM, Andujar-Sanchez M, Ortiz-Salmeron E, Neira JL, et al. Electrostatic effects in the folding of the $\mathrm{SH} 3$ domain of the c-Src tyrosine kinase: $\mathrm{pH}$-dependence in 3D-domain swapping and amyloid formation. PloS one. 2014;9:e113224.https://doi. org/10.1371/journal.pone.0113224 PMid:25490095 PMCid:PMC4260792.

37. Tzeng SR, Lou YC, Pai MT, Jain ML, Cheng JW. Solution structure of the human BTK SH3 domain complexed with a proline-rich peptide from p120cbl. Journal of biomolecular NMR. 2000;16:303-12.https://doi. org/10.1023/A:1008376624863 PMid:10826882.

38. Horita DA, Baldisseri DM, Zhang W, Altieri AS, Smithgall TE, Gmeiner WH, et al. Solution structure of the human Hck SH3 domain and identification of its ligand binding site. Journal of molecular biology. 1998;278:253-65. https:// doi.org/10.1006/jmbi.1998.1690 PMid:9571048.

39. Larson SM, Davidson AR. The identification of conserved interactions within the $\mathrm{SH} 3$ domain by alignment of sequences and structures. Protein science: a publication of the Protein Society. 2000;9:2170-80.https://doi.org/10.1110/ ps.9.11.2170 PMid:11152127 PMCid:PMC2144485.

40. Rickles RJ, Botfield MC, Zhou XM, Henry PA, Brugge JS, Zoller MJ. Phage display selection of ligand residues important for Src homology 3 domain binding specificity. Proceedings of the National Academy of Sciences of the United States of America. 1995;92:10909-13. https://doi.org/10.1073/ pnas.92.24.10909 PMid:7479908 PMCid:PMC40540.

41. Lee CH, Leung B, Lemmon MA, Zheng J, Cowburn D, Kuriyan J, et al. A single amino acid in the $\mathrm{SH} 3$ domain of Hck determines its high affinity and specificity in binding to HIV-1 Nef protein. The EMBO journal. 1995;14:5006-15. PMid:7588629 PMCid:PMC394604.

42. Pisabarro MT, Serrano L. Rational design of specific high-affinity peptide ligands for the Abl-SH3 domain. Biochemistry. 1996;35:10634-40. https://doi. org/10.1021/bi960203t PMid:8718852.

43. Ferguson MR, Fan X, Mukherjee M, Luo J, Khan R, Ferreon JC, et al. Directed discovery of bivalent peptide ligands to an $\mathrm{SH} 3$ domain. Protein science : a publication of the Protein Society. 2004;13:626-32.https://doi. org/10.1110/ps.03470504 PMid:14978303 PMCid:PMC2286729.

44. Kolb P, Irwin JJ. Docking screens: right for the right reasons? Current topics in medicinal chemistry. 2009;9:755-70. https://doi. org/10.2174/156802609789207091 PMid:19754393 PMCid:PMC3383315.

45. Tovchigrechko A, Wells CA, Vakser IA. Docking of protein models. Protein science : a publication of the Protein Society. 2002;11:1888-96. https://doi. org/10.1110/ps.4730102 PMid:12142443 PMCid:PMC2373684.

46. Ren $\mathrm{Y}$, Wang $\mathrm{Q}$, Chen $\mathrm{S}$, Cao $\mathrm{H}$. Integrating Computational Modeling and Experimental Assay to Discover New Potent ACE-Inhibitory Peptides Molecular Informatics Volume 33, Issue 1. Molecular Informatics. 2014;33:43-52. https://doi.org/10.1002/minf.201300131 PMid:27485198. 


\section{Pictorial Abstract}

A

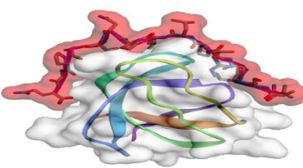

B
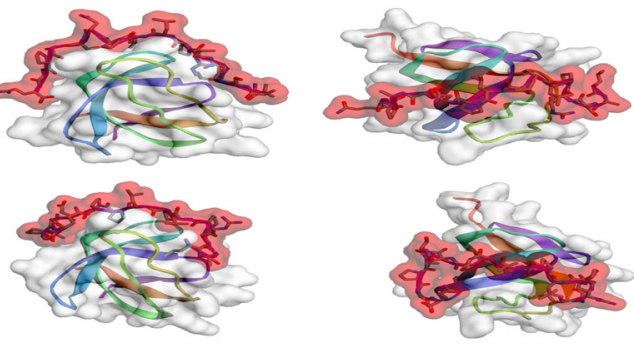

C

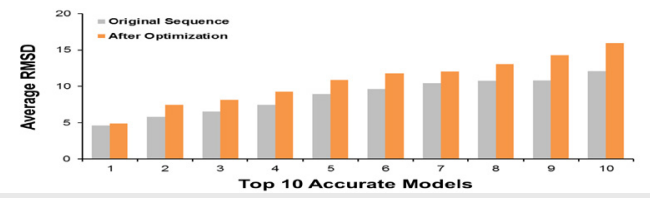

\section{SUMMARY}

- Promiscuous binding between anticancer peptide and multiple off-targets is a crucial challenge in biotechnology.

- Here we explored peptide ligands in MINT database and utilized SH3PepInt tool for in silico peptide-target binding.

- By optimizing the amino acid sequence of peptide ligands, we rendered high specificity towards the SH3 domain of c-Src target.

- These findings provided a unique opportunity for rational design of therapeutic peptides.

\section{About Authors}

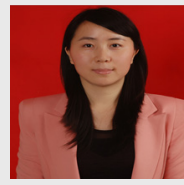

Yanrong Ren: Professor at Chongqing University of Education, whose major interest is theraputic peptide design and drug safety assessment.

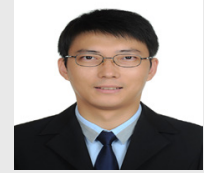

Qiang Wang: Expert on structures of therapeutic peptides at Chongqing University of Education.

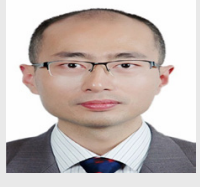

Xiaobo Li: Expert on human resource at Chongqing University of Education.

Cite this article: Ren Y, Wang Q, Li X. Optimizing the Amino Acid Sequences of Peptides and Improving Their Specificity of Binding to SH3 Domains of Target Proteins. Indian J of Pharmaceutical Education and Research. $2017 ; 51(1): 43-50$. 